\title{
A tool wear observer model for flank wear monitoring in the milling of Nickel-based alloys
}

\author{
H.Z. Li $i^{*}$
}

Singapore Institute of Manufacturing Technology,

71 Nanyang Drive, 638075, Singapore

E-mail: lihuaizhong@gmail.com

${ }^{*}$ Corresponding author

\author{
A. Albrecht \\ Bosch Rexroth AG, \\ P.O. Box 3002 40, \\ 70442 Stuttgart, Germany \\ E-mail: andreas.albrecht@boschrexroth.de
}

\section{X.Q. Chen}

Department of Mechanical Engineering,

The University of Canterbury,

Private Bag 4800, Christchurch 8140, New Zealand

E-mail: xiaoqi.chen@canterbury.ac.nz

\begin{abstract}
Tool wear monitoring is of great industrial importance in machining Nickel-based alloys. This paper presents the research effort to develop a tool wear observer model for flank wear monitoring in the milling of Nickel-based alloys. It aims at an online tool wear monitoring system that is capable of predicting tool wear in real time by measuring the cutting force variation. The correlation between the cutting force components and the flank wear width has been established through experimental studies. An observer model is developed to estimate the flank wear growth from the measured cutting force signals.
\end{abstract}

Keywords: tool wear; tool condition monitoring; milling; nickel-based alloys; observer model.

Reference to this paper should be made as follows: Li, H.Z., Albrecht, A. and Chen, X.Q. (2009) 'A tool wear observer model for flank wear monitoring in the milling of Nickel-based alloys', Int. J. Mechatronics and Manufacturing Systems, Vol. 2, Nos. 5/6, pp.620-637.

Biographical notes: Huaizhong $\mathrm{Li}$ received his BEng from Tsinghua University, China, in 1988; MEng from Xi'an Jiaotong University, China, in 1991 and $\mathrm{PhD}$ from National University of Singapore in 2002. He has long-term $R \& D$ and industrial experience in the areas of manufacturing technology, sensing, signal processing and diagnosis of machinery, vibration 
control, and mechatronics. He was Senior Research Engineer at Singapore Institute of Manufacturing Technology (2001-2008), and Research Associate at the University of New South Wales (2008). Currently he is Associate Principal Engineer with Vestas Technology R\&D Singapore Pte Ltd.

Andreas Albrecht had worked as an attachment student with Singapore Institute of Manufacturing Technology for six months (2001-2002). He obtained his Engineering Degree (German Dipl.- Ing.) in 2003, with his thesis being written at the Manufacturing Automation Laboratory, University of British Columbia, Canada, where he worked for seven months. Later he got a position within the $\mathrm{PhD}$ programme of the Robert Bosch $\mathrm{GmbH}$ in Schwieberdingen. In October 2006, he joined Bosch Rexroth AG as a development engineer in the mobile hydraulics area. His research interests include system dynamics, controller design and optimisation, and hardware-in-the-loop-simulation.

Xiaoqi Chen obtained his BE Degree from South China University of Technology in 1984. He was a recipient of China-UK Technical Co-Operation Award. He obtained his MSc Degree from Brunel University in 1986, and PhD Degree from the University of Liverpool in 1989. He was senior research assistant at University of Durham (1989-1990), research fellow at Brunel University (1990-1992), and senior scientist in Singapore Institute of Manufacturing Technology (1992-2006). He received Singapore National Technology Award in 1999. Currently, he is Associate Professor, and Director for Mechatronics Engineering at University of Canterbury.

\section{Introduction}

There have been intensive research efforts aiming at machine tool condition monitoring and smart machining, in recent years (Fong et al., 2002; Li et al., 2007). To meet the requirements of harsh and corrosive working environments in aircraft engines and gas turbines, Nickel-based super alloys and Titanium alloys have been widely used. Unfortunately, these alloys tend to work-hardening and adhesion, and are hard-to-machine. Tool wear is a severe problem in milling Nickel-based alloys such as Inconel. As tool wear deteriorates the accuracy and surface finish of the parts being machined, tools have to be replaced in time. Hence, tool wear monitoring is of great importance in milling Nickel-based alloys. However, this is still a task that has not been solved satisfactorily yet. In metal machining, it is very difficult, if not impossible, to directly monitor the tool wear development in real time due to the lack of suitable sensors. On the other hand, there is a pressing industry need for online tool wear monitoring systems that are capable of measuring, or at least predicting, the actual state of tool wear in real time by measuring other process quantities.

A general effect of tool wear is an increase of the cutting forces and the process temperature. Exploring the relationship between tool wear propagation and cutting force variation is of great importance in the development of an effective tool condition monitoring strategy. Komanduri and Schroeder (1986) investigated the shear instability and the deformation in chips produced in machining Inconel 718 at various speeds. 
Hanasaki et al. (1990) studied the tool wear in the turning of a high nickel alloy with four representative coated tools, and reported that in using coated tools, the flank groove wear was reduced and the tool life was determined by the boundary wear instead of the flank groove wear. Byrne and Bienia (1991) found that TiN coated HSS was suitable for the machining of high nickel content, soft magnetic materials from a tool life point of view, although a large scatter in tool life occurred. Ezugwu et al. (2001) investigated the performance of multiplayer-coated carbide tools in the turning of a martensitic stainless steel without coolant, and found that the predominant failure modes at higher speed conditions were significant nose wear and chipping/fracture of the cutting edge. In recent years, Alauddin et al. (1998) studied the influence of the machining conditions on the average cutting forces in the end milling of Inconel 718 under dry conditions using uncoated carbide inserts, but the problems of tool wear were not addressed. $\mathrm{Ng}$ et al. (2000) studied the effects of cutter orientation, tool coating and cutting environment on tool life, tool wear mechanisms, cutting forces, chip formation, cutting temperature and workpiece surface roughness, during high speed ball nose end milling of Inconel 718. Li et al. (2006) conducted an experimental study of the tool wear propagation and cutting force variations in the end milling of Inconel 718 with coated carbide inserts. The results showed that significant flank wear was the predominant failure mode affecting the tool life. The tool flank wear propagation in the up milling operations was more rapid than that in the down milling operations. It was proposed that the relationship between tool wear propagation and cutting force variation can be used to develop effective tool condition monitoring strategies.

As the process of tool wear is very complex and is influenced by various factors, a promising method to monitor tool wear seems to be the model based approach. A simple mechanistic model to approximate atypical flank wear behaviour was introduced in Weber and Loladze (1986) as shown in Figure 1. The model consists of a stable PT1-block representing the wear-in process, an integrator block for the steady state wear, and an instable PT1-block for the exponential growth of wear land towards the end of tool life. The machined length, or the machining time, is used as an input parameter. The model outputs the estimated flank wear width. Model parameters have to be adjusted using experimental data. If a parameter estimating algorithm like the root least squares method is implemented in a feed-back loop, model parameters can be updated online corresponding to the values measured in the real process. The model may then serve as an adaptive tool wear observer. The adaptive observer principle (Park and Ulsoy, 1993a) is shown in Figure 2. Examples of adaptive tool wear observer models can be found in Park and Ulsoy (1993a, 1993b, 1992), Koren et al. (1986), Koren (1987), Novak and Wiklund (1996), Danai and Ulsoy (1987a, 1987b). An indirect approach has been studied in Koren (1987) to develop a model for the correlation between cutting forces and flank wear for turning processes. The increase of cutting forces was used to estimate the growth of flank wear by using an adaptive process observer model designed for the turning process of steel. This model estimates the actual state of flank wear using cutting force measurements as an indirect tool wear indicator. The model parameters were derived from force and flank wear measurements carried out during turning experiments. However, growth of tool wear does not always behave in the same way, as tool life and wear rate may scatter in a wide range around average values even if cutting parameters are kept constant. To make the above model more flexible and robust against variations of tool wear rate and cutting forces during machining, an additional 
parameter estimator block was implemented, that can adjust the model parameters online by using a feed back loop.

Figure 1 Straight-forward model to approximate flank wear behaviour (see online version for colours)
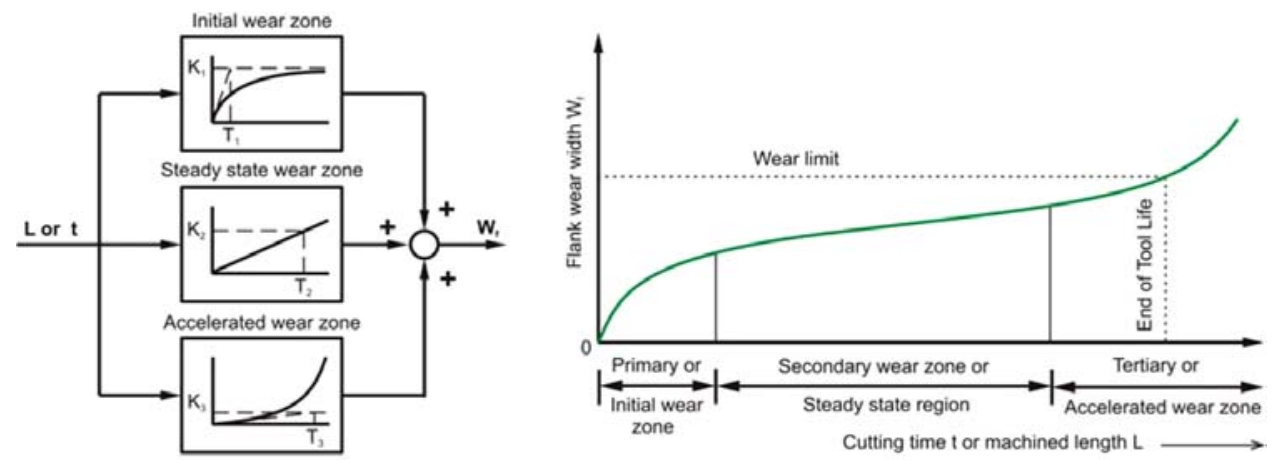

Source: Weber and Loladze (1986)

Figure 2 Principle of an adaptive observer model (see online version for colours)

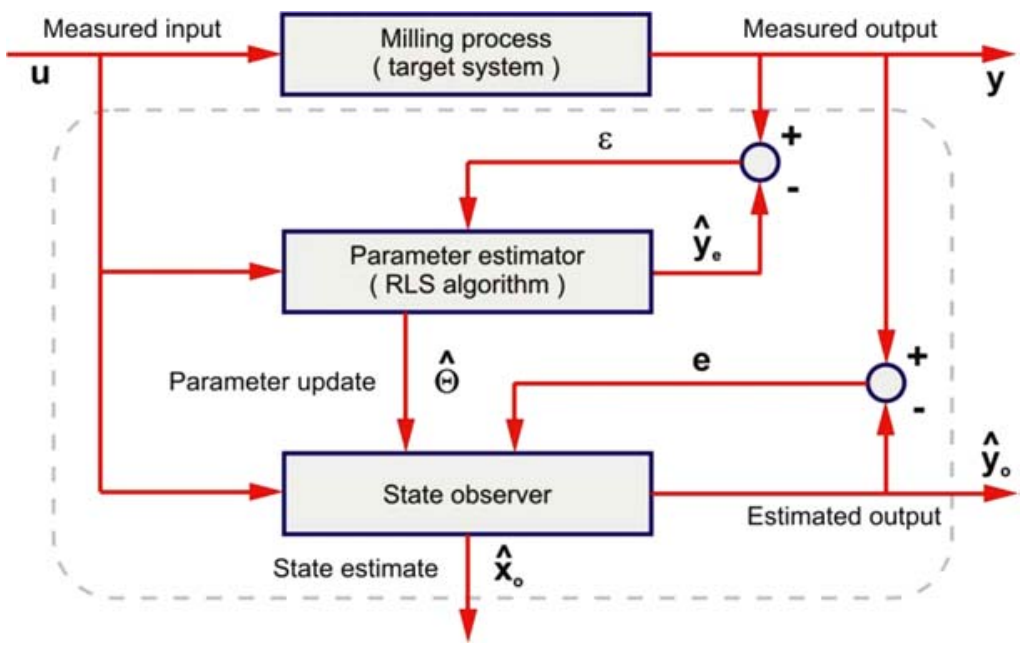

Source: Park and Ulsoy (1993a)

Other different approaches have also been studied in recent years (Kuljanic and Sortino, 2005; Shi and Gindy, 2007; Iqbal et al., 2007). Kuljanic and Sortino (2005) investigated the characteristics of cutting forces in face milling measured with a rotating dynamometer and the influence of tool wear on cutting forces with emphasis on the study of tool wear indicators such as Normalised Cutting Force (NCF) and Torque Force Distance (TFD) indicators. They proposed a Tool Wear Estimation Method (TWEM) for tool condition monitoring in face milling with one tooth cutter or multi-tooth cutter, when the pitch of the cutter is greater than the width of the workpiece. 
Shi and Gindy (2007) proposed a tool wear predictive model using a combination of the Least Squares Support Vector Machines (LS-SVM) and the Principal Component Analysis (PCA) technique, using multiple sensory signals. In Iqbal et al. (2007), the application of artificial intelligence to the domain of hard milling process using two strategies was introduced. It was shown that cutting force signals give better real time information about condition of in-progress machining process. However, there is still a far way to go for industrial applications.

In this paper, we will further develop a model using control theory, and apply it to milling processes for the tool wear monitoring in cutting a Nickel based super-alloy. As a step towards the development of an online tool wear monitoring system, this study aims to develop a process observer model for predicting the flank wear in the milling of Inconel material. It begins from the correlation to reconstruct the actual flank wear width from the measured cutting force signal. This model was further developed into a state observer. An adaptive state observer could be obtained by adding a parameter estimator based on the recursive least-squares algorithm to the state observer model. The development of the model and experimental studies are presented in this paper.

\section{Experimental study and tool wear: force correlation}

To study the tool wear behaviours and to establish a correlation between the tool wear development and cutting force variation that can be used to develop a tool wear observer model, a series of cutting experiments have been accomplished systematically. The experimental setup was shown in Figure 3. The machine tool used in the cutting test was a SHOWA 3-axis vertical milling machine tool with a PC-based $\mathrm{NC}$ controller. The machine table could be moved in Cartesian coordinates in the $x, y$-, and $z$-directions. A batch of 4-flute YG-1 bull-nose end mills were used for the tool wear experiments. The cutter diameter is $8 \mathrm{~mm}$. Its basic material is tungsten carbide M612, with a coating of TiAlN.

Figure 3 The experimental setup (see online version for colours)

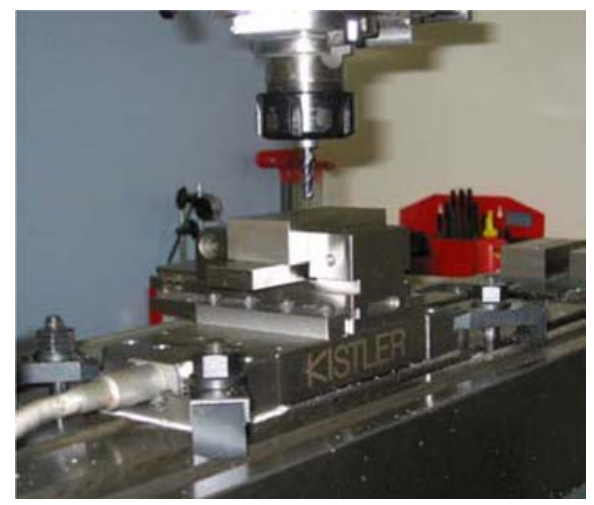


The work material is Inconel 718. Inconel 718 is a precipitation-hardenable Nickel-Chromium alloy containing significant amounts of iron, niobium, and molybdenum along with lesser amounts of aluminium and titanium. This alloy combines desirable properties like high strength with outstanding durability and corrosion resistance. The alloy has excellent creep-rupture strength at temperatures up to $700^{\circ} \mathrm{C}$. It is commonly used in high-end applications like gas turbines, rocket motors, spacecrafts, nuclear reactors, pumps, or tooling where these properties are required. Inconel 718 is a very difficult-to-machine material. It has a very high yield stress level, but also tends to adhesion and work-hardening. Due to the properties of Inconel, process instability, heavy cutting edge chipping, severe tool wear, and built-up edges on the rake faces of cutting tools can be observed as the thermal and mechanical loads acting on them are enormous. When machining Inconel 718 at elevated process temperatures the cutter material often loses its strength quicker than the work material itself, as the latter is very temperature resistant.

The workpieces were prepared in blocks with approximate dimensions of $105 \mathrm{~mm} \times 50 \mathrm{~mm} \times 30 \mathrm{~mm}$. The block was clamped in a vice that, in turn, was mounted on a piezo quartz force dynamometer. The piezo quartz force dynamometer was fixed on the machine table with four straps. The dynamometer was aligned with the milling machine's $x$-axis. Full immersion, or slot milling, was chosen as immersion condition. The machining direction was parallel to the machine's $x$-axis. The parameter settings for the tool wear testing are given in Table 1 .

Table 1 Cutting parameter settings for tool wear experiments

\begin{tabular}{lccc}
\hline Spindle speed (rpm) & 800 & 1000 & 1200 \\
\hline Feed rate ft (mm/tooth) & 0.0075 & 0.0075 & 0.0075 \\
& 0.0100 & 0.0100 & 0.0100 \\
& 0.0125 & 0.0125 & 0.0125 \\
& 0.0150 & 0.0150 & 0.0150 \\
\hline
\end{tabular}

Unit depth of cut: ap $=0.5 \mathrm{~mm}$

To obtain a tool wear curve, a slot was milled on the workpiece and the cutting forces were measured with the piezo quartz dynamometer. The cutting force data were then captured by a PC for further analysis and evaluation. After finishing one slot, the tool was removed from the chuck to observe the cutter flutes under the microscope and to measure the amount of tool wear. The state of tool wear was measured on all four flutes and the average value was calculated. When tool wear evaluation was completed another slot was machined.

The experiments showed that flank wear and edge chipping were dominating. There was no crater wear observed. As Nickel-based alloys like Inconel strongly tend towards adhesion, built-up edges could sometimes be observed, too. Some work material sticking to the cutter flutes was removed carefully before the flutes were observed under the microscope. The built-up edges were rather small and did not adhere strongly to the cutter. Removing the built-up edges was necessary to prevent any false interpretation of the tool wear images. 
To measure the maximum flank wear width, a reference edge was required. However, the original cutting edges were steadily chipped off during the tool wear experiments, and thus, the reference edges were removed. As a replacement, the projection of the cutter flute's rake face on the focus plane of the microscope was used. Therefore, the end mill cutter was oriented in such a way that the rake face of the flute to be observed was approximately perpendicular to the microscope's focus plane (parallel to the view direction), and its worn flank face could be seen clearly. The maximum chipped edge width was introduced to characterise the extent of edge chipping. It reduces the bizarre and complicated geometry of any chipped-off cutting edge to a simple numeric value representing the approximate state of edge chipping similar to the maximum flank wear width. It is just meant to indicate the approximate development of breakouts on the cutting edge. Two photos to depict the maximum flank wear width and the maximum chipped edge width on a worn cutter flute at different states of wear are given in Figure 4.

Figure 4 Maximum flank wear width and maximum chipped edge width on a cutter flute (see online version for colours)
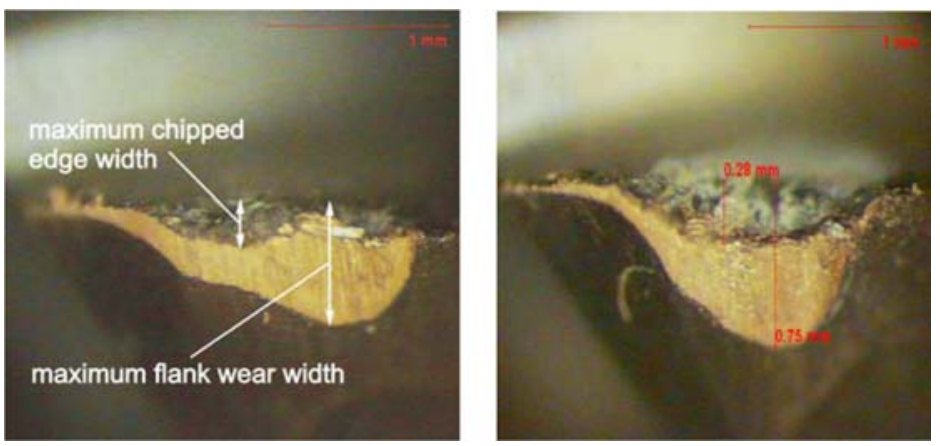

The results for the development of the maximum flank wear width and the maximum chipped edge width vs. the machined length under different cutting conditions are presented in Figures 5 and 6, respectively. It shows that the development of the flank wear and edge chipping was approximately linear over the whole machining length for the tools running at lower spindle speeds of $800 \mathrm{rpm}$ and $1000 \mathrm{rpm}$, in spite of different feedrates. However, for higher spindle speeds of $1200 \mathrm{rpm}$, an exponential or accelerated wear zone occurred. The end of tool life was thus reached much quicker. One sample tool was tested at $1500 \mathrm{rpm}$ but tool life ended very soon after $12 \mathrm{~cm}$ machined length with heavy glooming, excessive flank wear, and heavy edge chipping. The tool was overheated. It was noted that edge chipping and flank wear behaviour were almost analogue in both the steady state and the accelerated wear zone at $1200 \mathrm{rpm}$.

In contrast to the flank wear width, the chipped off edge width could decrease as well. This was believed to be caused by the self regrinding effect. As the tool continuously wears off at its flank face, any breakouts might be grinded away after a while if no further breakouts occur. Edge chipping itself has rather random character, at least the geometry of the breakouts does. 
Figure 5 Development of the maximum flank wear width vs. the machined length (see online version for colours)

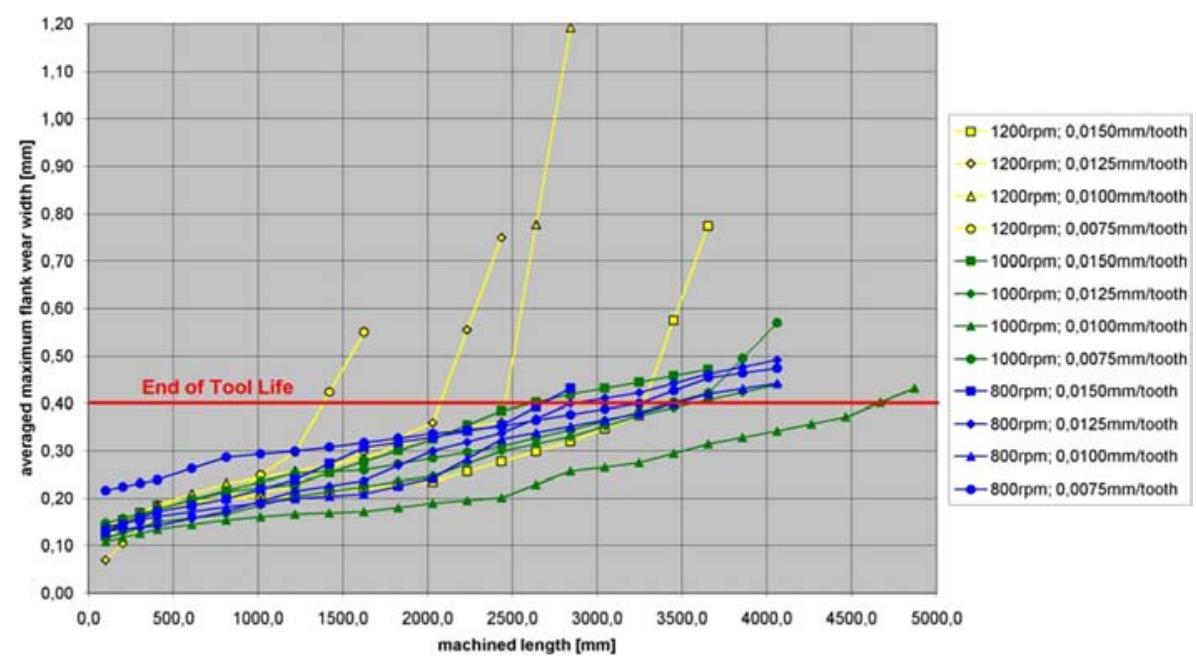

Figure 6 Development of the maximum chipped edge width vs. the machined length (see online version for colours)

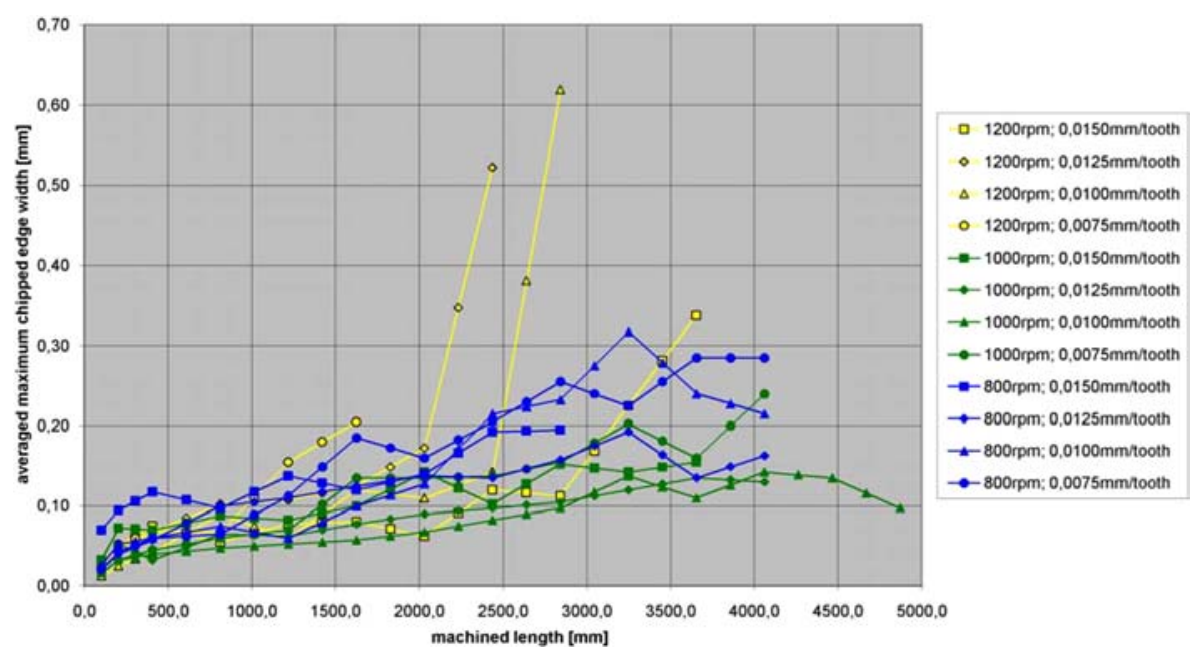

To explain the differences in the wear behaviour at lower spindle speeds $(800 \mathrm{rpm}$ and $1000 \mathrm{rpm})$ in contrast to higher spindle speed $(1200 \mathrm{rpm})$, the focus has to be on the wear mechanisms that caused flank wear and edge chipping in this specific case. Since dry cutting was applied and Inconel 718 is a very hard and tough work material, abrasion was definitely one of the dominating wear mechanisms. Small scratches and scores can be observed on the flank wear land, which are typical marks for abrasion wear. Similar scoring marks could be observed on the flanks of the other tools no matter what cutting parameters were set. Another important tool wear mechanism in Inconel machining is adhesion. The work material adheres to the cutting tool but this metal connection is unstable and separates again when the 
tool is moved on. Thus, small particles are torn off the tool material, which boosts flank wear.

Abrasion, as well as adhesion, can be regarded as mechanically activated wear. They occur at both low and high cutting temperatures, and are mainly dependent on the lubrication conditions, contact loads between tool and work material, and the tool-work material combination. At lower cutting speeds only mechanically activated wear mechanisms occur. However, if cutting speeds and, thus, cutting temperatures increase, thermally activated wear has to be considered too. When the tool material is heated it loses its strength and diffusion may occur. Hence, tool wear rate increases. This was exactly the case in the cutting experiments with spindle speeds of $1200 \mathrm{rpm}$ and above. The dissipated process energy was high enough to weaken the tool material noticeably. Thus, the tool wear rate grew exponentially towards the end of tool life. At lower spindle speeds the dissipated energy was too low to weaken the tool material, and it could resist longer.

A main task of this study was to examine and analyse the experimental results of tool wear and cutting force measurements on suitable correlations between the characteristic quantities of the cutting force signal and the growth of tool wear. The most characteristic quantities of the cutting force signal that might be useful to indicate tool wear indirectly had to be identified. Figures 7-9 show the time domain quantities calculated from the cutting force data with the parameter set of spindle speed $1200 \mathrm{rpm}$, feed rate $0.0150 \mathrm{~mm} /$ tooth as an example. There was a steady increase of the averaged maximum peak value, mean value, and root mean square value of the cutting force signal in $x-, y$-, and $z$-direction vs. the machined length. Similar behaviour could also be observed for all other parameter sets.

Figure 7 Variations of the force signal characteristics in $x$-direction (1200 rpm, $0.0150 \mathrm{~mm} /$ tooth) (see online version for colours)

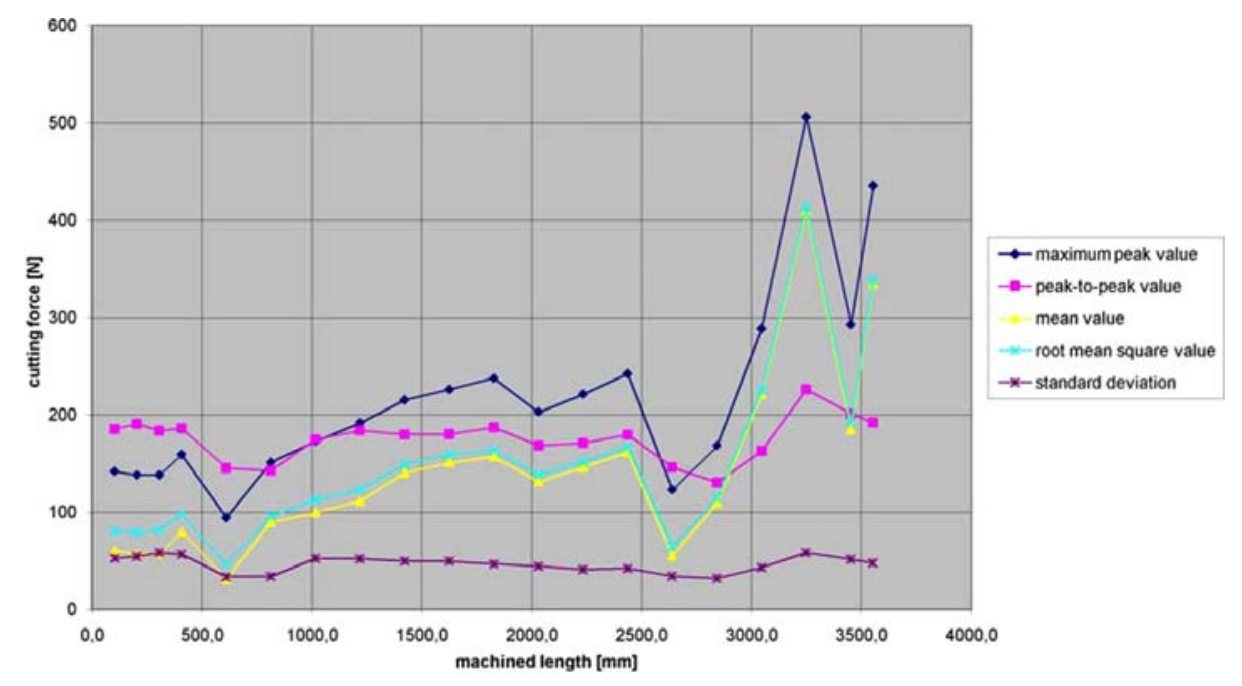


Figure 8 Variations of the force signal characteristics in $y$-direction (1200 rpm, $0.0150 \mathrm{~mm} /$ tooth) (see online version for colours)

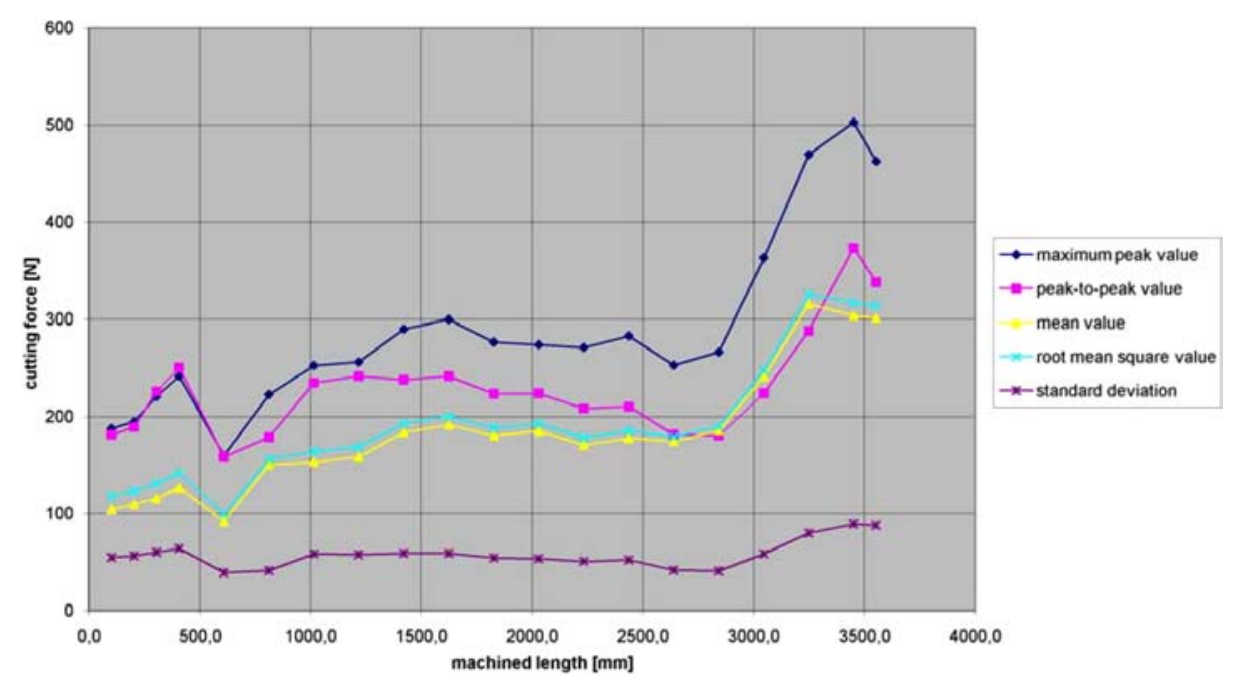

Figure 9 Variations of the force signal characteristics in $z$-direction $(1200 \mathrm{rpm}, 0.0150 \mathrm{~mm} /$ tooth $)$ (see online version for colours)

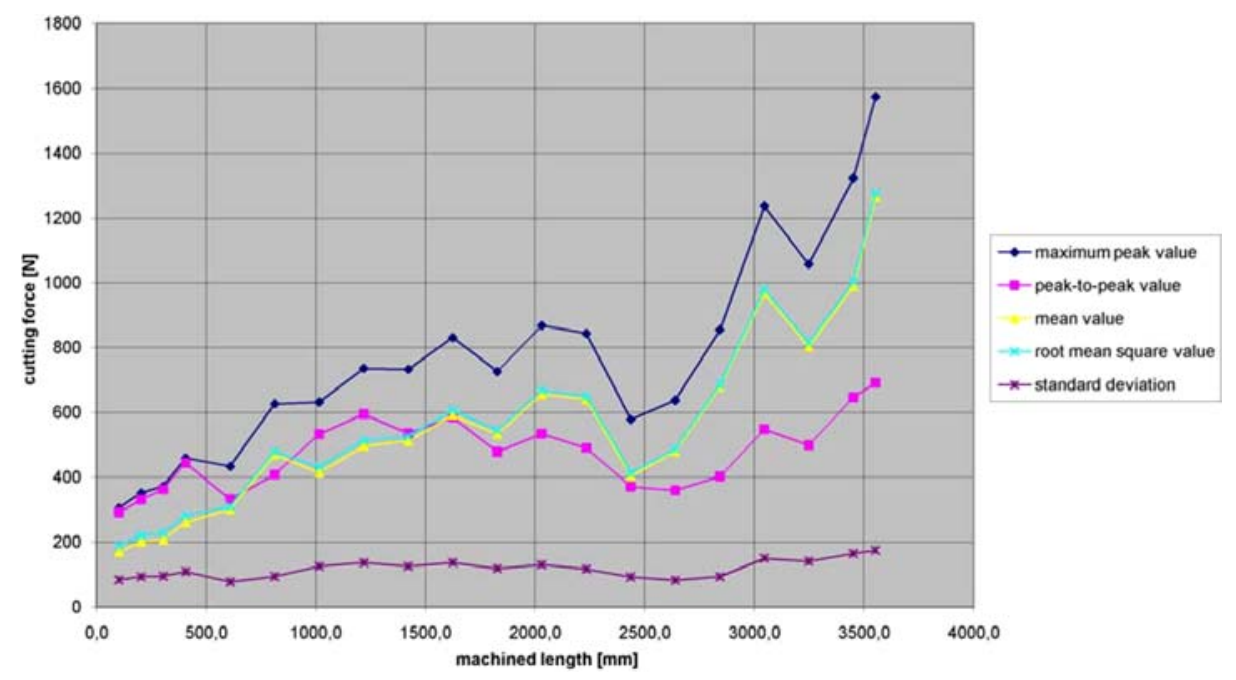

Figure 10 shows the graphs of both maximum flank wear and chipped edge width as well as the mean value of the cutting force components in $x-, y$-, and $z$-direction vs. the milled length and the number of spindle revolutions. The mean value of all three force components increased steadily with the machined length and growing flank wear width. It was noted that the increase was most obvious for the force component in $z$-direction. Particularly striking out is the almost parallel course of the graphs of flank wear width and mean value of the cutting force component in $z$-direction. So, there seems to be some linear correlation between the mean value of the cutting force signal and the flank wear width on the cutter teeth as similar behaviour could be observed with all other parameter sets, too. 
Figure 10 Development of tool wear and mean/average value of all three cutting force components (1000 rpm, $0.0075 \mathrm{~mm} /$ tooth) (see online version for colours)

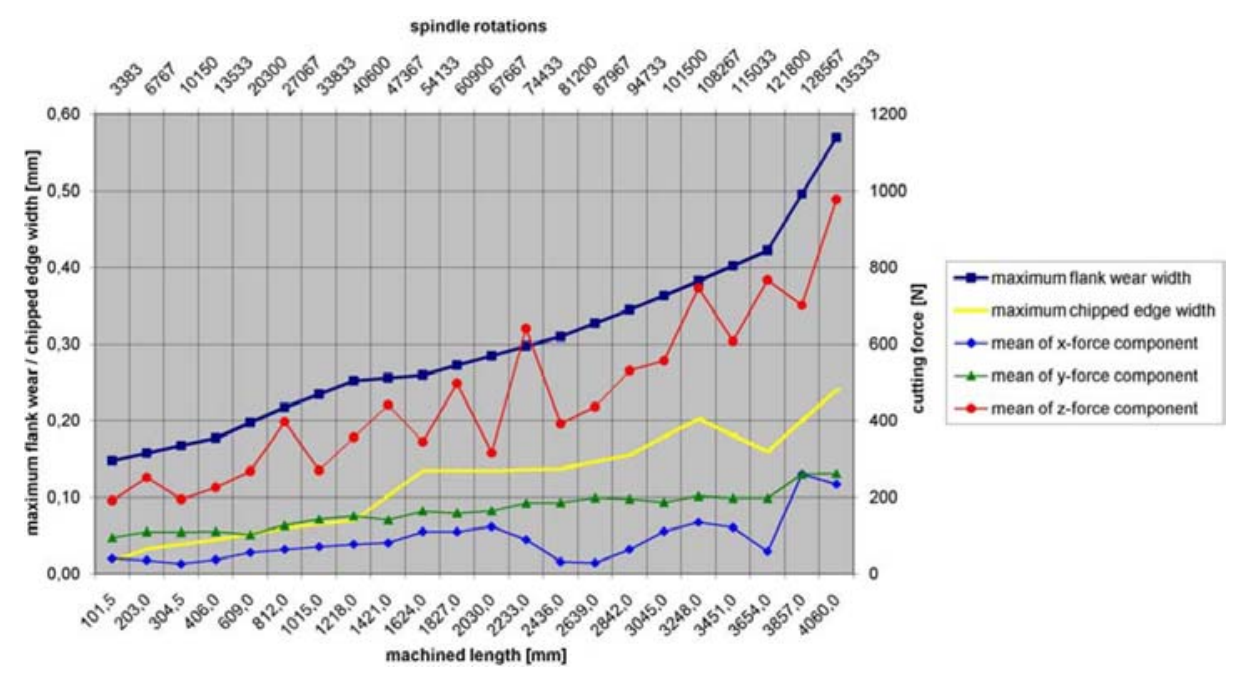

The assumption can be confirmed by plotting the mean values of the force components vs. the corresponding flank wear widths, with an example for the cutting condition of $800 \mathrm{rpm}, 0.0125 \mathrm{~mm} /$ tooth as depicted in Figure 11. If the root mean square value is used instead of the mean value similar diagrams can be obtained. All three cutting force components seem to be proportional to the flank wear width with different proportionality constants. The inclination of the force component in the $z$-direction vs. increasing tool wear is the largest of all, but this force component is also the most disturbed. The force component in $y$-direction is least disturbed.

Figure 11 Cutting force components vs. flank wear width $(800 \mathrm{rpm}, 0.0125 \mathrm{~mm} / \mathrm{tooth})$ (see online version for colours)

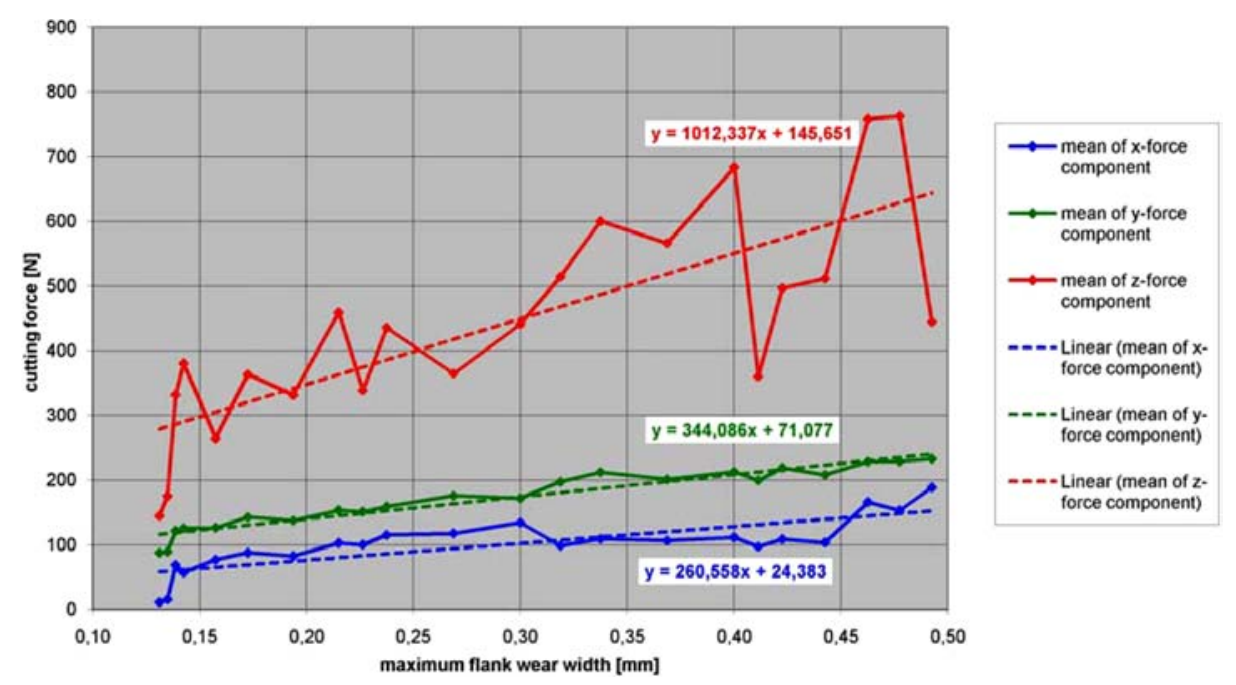


In Figure 11, the initial force at zero flank wear width is positive for all three force components but that was not the general case. Two other examples are given in Figure 12 for the cutting conditions of $1000 \mathrm{rpm}, 0.0075 \mathrm{~mm} /$ tooth, and Figure 13 for $1200 \mathrm{rpm}, 0.0125 \mathrm{~mm} /$ tooth. In Figure 13, there is a clear deviation from the forces predicted by the linear approach and the measured forces for the initial wear zone, respectively, for small flank wear widths. In this case, a partially non-linear approach that puts less emphasis on the force raising effect of the initial wear would be more suitable.

Figure 12 Cutting force components vs. flank wear width (1000 rpm, $0.0075 \mathrm{~mm} /$ tooth) (see online version for colours)

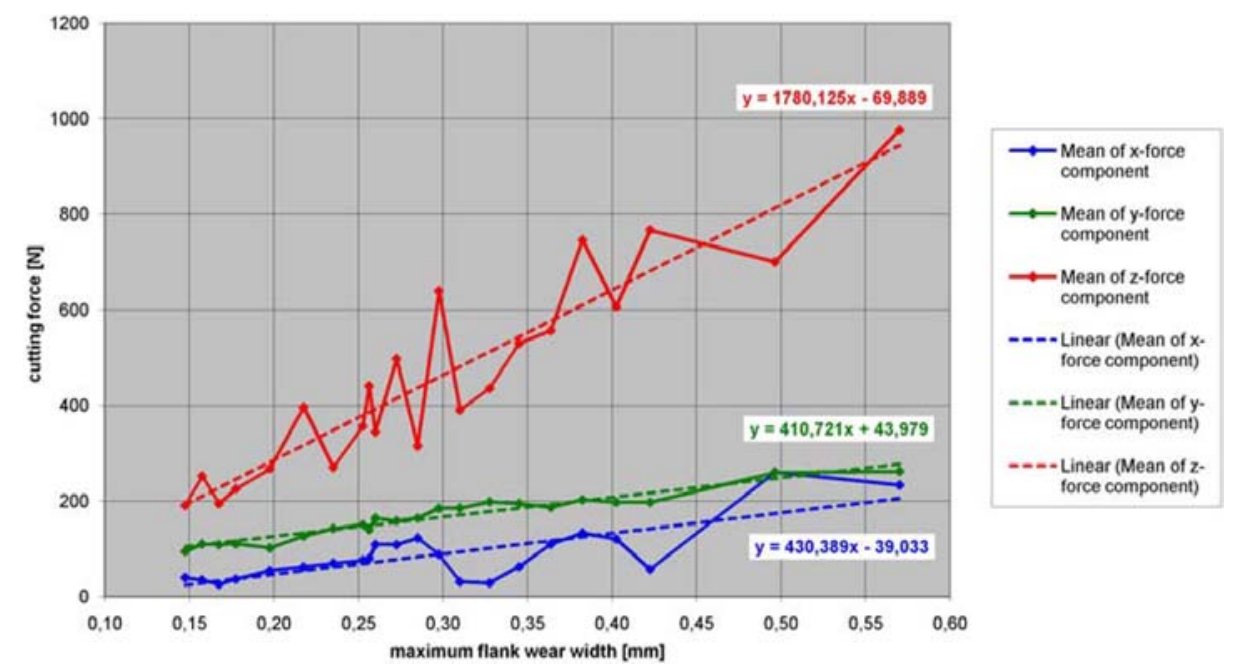

Figure 13 Cutting force components vs. flank wear width (1200 rpm, $0.0125 \mathrm{~mm} /$ tooth) (see online version for colours)

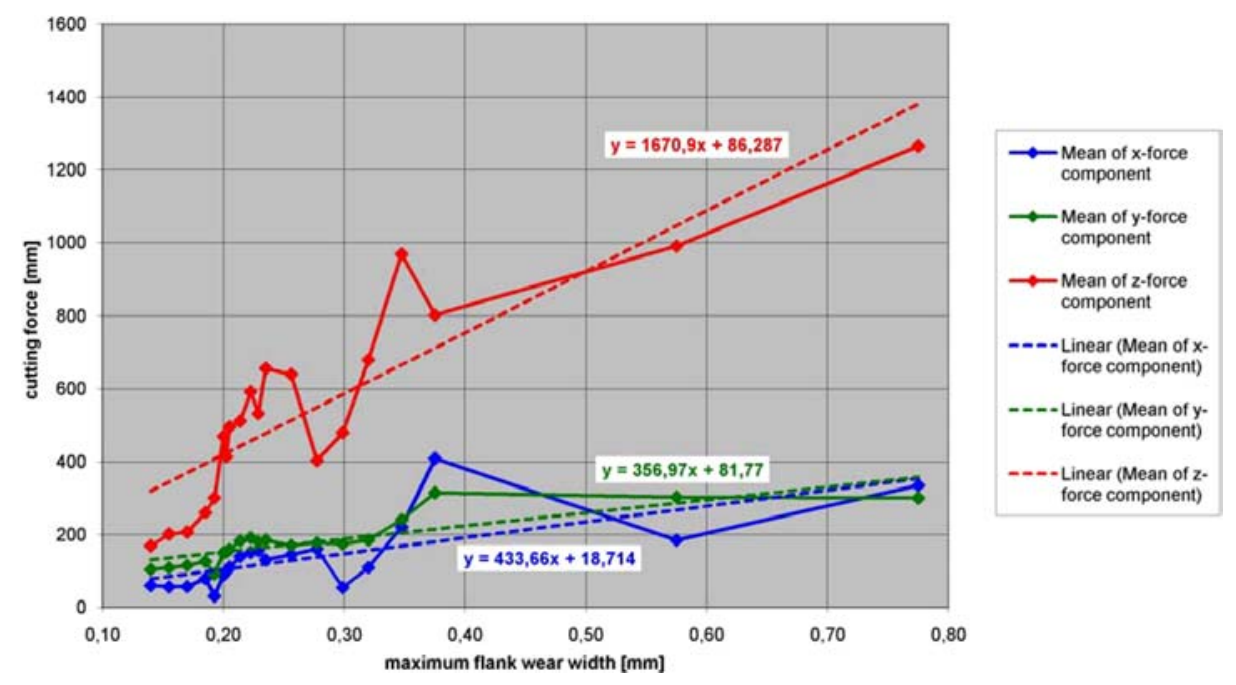


In Figure 14 two different approaches for the correlation between mean value or RMS-value of the cutting force components and maximum flank wear width are presented. The linear approach expresses the cutting force components as the sum of an initial value plus the flank wear width times a constant. In the non-linear approach, an additional correction term is subtracted from the linear approach, so, that the effect of flank wear on the cutting forces is delayed. In most cases, the linear approach seems to be sufficient. The parameters for these two approaches can be found by regression analysis as is depicted in Figure 14 for both approaches.

Figure 14 Two approaches for the correlation between cutting force and flank wear width (see online version for colours)

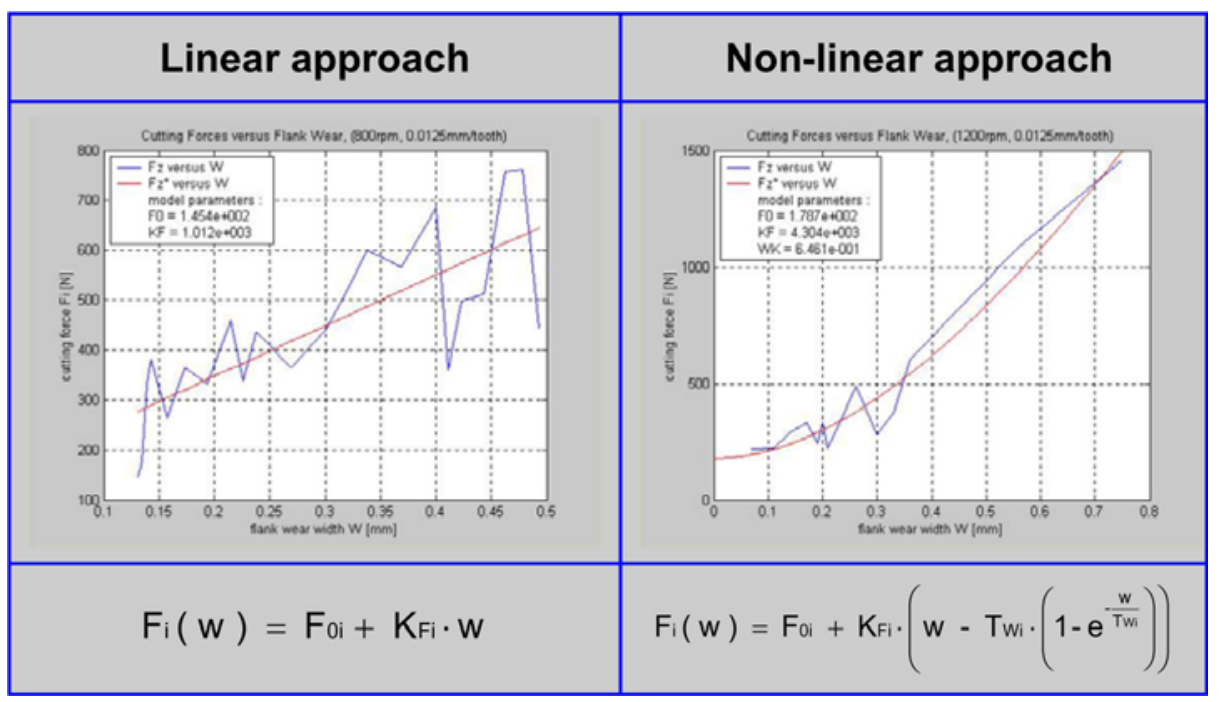

\section{Development of the tool wear model}

The proposed process observer model for predicting the flank wear in the milling of Inconel material is depicted in block representation in the Laplace domain as shown in Figure 15. It was developed based on a model in Koren (1987) for turning process. It consists of two forward branches and a feed back loop. The input of the model is the initial force that can be derived from the machining parameters such as spindle speed, feed rate, depth of cut, tool geometry, work material, etc. The equation for the initial force dependent of the machining parameters can be determined empirically by cutting experiments for the specific tool and work material combination used, or from an analytical model. The output of the model is the estimated flank wear width. The cutting force is an intermediate quantity that sums up of the initial force and the force variation caused by flank wear. The force variation is calculated in the feed back loop by using the linear model approach based on the experimental results. 
Figure 15 Modified flank wear observer model based on Koren (1987) (see online version for colours)

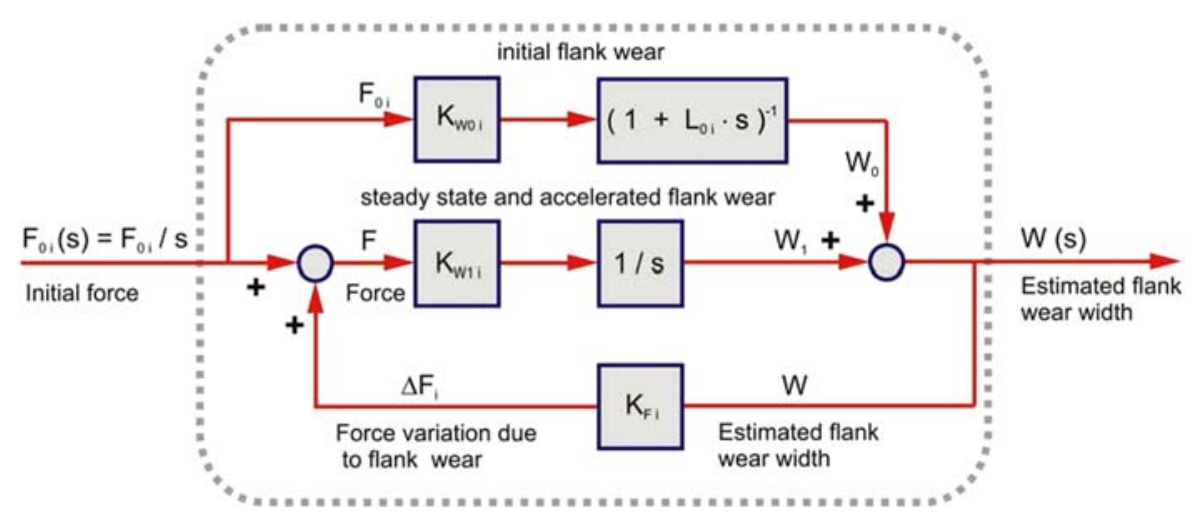

The flank wear width $W(s)$ is a summation of $W_{0}(s)$ and $W_{1}(s)$, where $W_{0}(s)$ represents the mechanically activated initial wear that rises quickly at the beginning of tool life and saturates after some time if cutting conditions are kept constant, as is the case in slot milling. $W_{1}(s)$ stands for the thermally activated wear, and also comprises mechanically induced wear in the steady state and accelerated wear zone.

If the initial force components are $F_{0 i}$, where $i$ is an index representing the three coordinate directions of the cutting forces, i.e., $x-z$, then, in this linear approach the current cutting force components can be expressed as

$$
F_{i}(s)=F_{0 i}(s)+K_{F i} \cdot W(s)
$$

where $W(s)$ is the flank wear width which is

$$
W(s)=W_{0}(s)+W_{1}(s) .
$$

For slot milling the model input, i.e., the initial force, can be represented by a step

$$
F_{0 i}(s)=\frac{F_{0 i}}{s}
$$

The initial wear $W_{0}(s)$ is modelled by using a first order delay block and can expressed as

$$
W_{0}(s)=\frac{K_{W 0 i}}{s \cdot\left(1+L_{0 i} \cdot s\right)} \cdot F_{0 i}
$$

The steady state and accelerated flank wear $W_{1}(s)$ is obtained by integrating the sum of the initial force and the force variation derived from the feed back loop and one obtains

$$
W_{1}(s)=\frac{K_{W 1 i}}{s} \cdot\left(F_{0 i}(s)+K_{F i} \cdot W(s)\right)
$$

From equation (2) we have

$$
W(s)=\frac{K_{W 0 i} \cdot F_{0 i}}{s\left(1+L_{0 i} \cdot s\right)}+\frac{K_{W 1 i}}{s} \cdot \frac{\S}{\text { (c) } s}+K_{F i} \cdot W(s)_{i} .
$$


Solving equation (6) for $W(s)$ yields

$$
W(s)=\frac{K_{W 0 i} \cdot F_{0 i}}{L_{0 i}} \cdot \frac{1}{\left(s-K_{W 1 i} \cdot K_{F i}\right)\left(s+1 / L_{0 i}\right)}+K_{W 1 i} \cdot F_{0 i} \cdot \frac{1}{s\left(s-K_{W 1 i} \cdot K_{F i}\right)} .
$$

Taking an inverse Laplace transformation of equation (7) gives the relationship of flank wear and the machined length if it is assumed that the feed rate was kept constant while a cutter was worn off in the cutting process, that is,

$$
W(L)=\frac{\S}{\mathrm{C}+K_{W 1 i} K_{F i} L_{0 i}}+\frac{F_{0 i}}{K_{F i}} \cdot \cdot\left(\mathrm{e}^{K_{W i i} K_{F i} L}-1\right)+\frac{K_{W 0 i} F_{0 i}}{1+K_{W 1 i} K_{F i} L_{0 i}} \cdot \stackrel{\S}{\S} \mathrm{e}^{-\frac{L}{L_{0 i}}}-1 .
$$

Similarly, the cutting force $F_{i}(s)$ can, thus, be expressed as follows

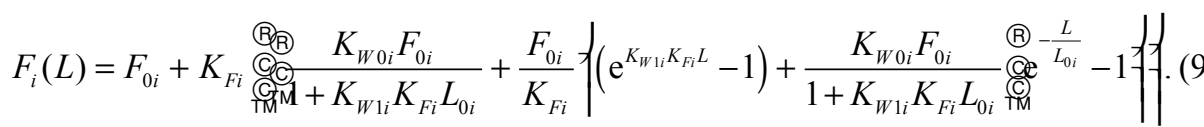

To create an online tool wear observer, the flank wear model should be converted into a state observer format. The flank wear model presented in Figure 15 is a linear dynamic system with the initial cutting force $F_{0}$ as input and flank wear $W$ as output variable. As flank wear cannot be measured online by sensors, it cannot be used as an output variable in the general observer form but as a state variable. Instead, the measurable cutting force is suitable as the output variable and can replace the flank wear in the previous model form.

When choosing the flank wear components $W_{0}$ and $W_{1}$ as state variables, the initial cutting force $F_{0}$ as input, and the total cutting force $F$ as output variable, the previous model can be modified as follows:

$$
\begin{aligned}
& s \cdot W_{0}(s)=-\frac{1}{L_{0 i}} \cdot W_{0}(s)+\frac{K_{W 0 i}}{L_{0 i}} \cdot F_{0 i}(s) \\
& s \cdot W_{1}(s)=K_{W 1 i} \cdot K_{F i} \cdot W_{0}(s)+K_{W 1 i} \cdot K_{F i} \cdot W_{1}(s)+K_{W 1 i} \cdot F_{0 i}(s) \\
& F_{i}(s)=K_{F i} \cdot W_{0}(s)+K_{F i} \cdot W_{1}(s)+F_{0 i}(s) .
\end{aligned}
$$

If $W_{0}(L=0)=0$ and $W_{1}(L=0)=0$ is assumed, taking the inverse Laplace-transformation of equations (10)-(12) yields the time-domain relationship

$$
\begin{aligned}
& \dot{W}_{0}(L)=-\frac{1}{L_{0 i}} \cdot W_{0}(L)+\frac{K_{W 0 i}}{L_{0 i}} \cdot F_{0 i}(L) \\
& \dot{W}_{1}(L)=K_{W 1 i} \cdot K_{F i} \cdot W_{0}(L)+K_{W 1 i} \cdot K_{F i} \cdot W_{1}(L)+K_{W 1 i} \cdot F_{0 i}(L) \\
& F_{i}(L)=K_{F i} \cdot W_{0}(L)+K_{F i} \cdot W_{1}(L)+F_{0 i}(L) .
\end{aligned}
$$

This is the desired general observer form of the flank wear model from Figure 15. Rearranging equations (13)-(15) yields the matrix representation of the state-space observer model 


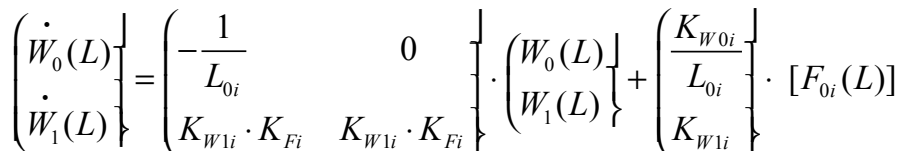

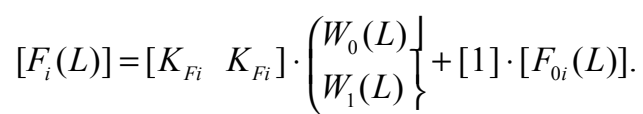

Equations (16) and (17) represent the continuous state observer form of the flank wear model. By converting it into a discrete format, it can be used for application on a digital computer to estimate the flank wear development provided that the model parameters are set correctly. Hence, it can be used as a state observer by using the measurable cutting force signal as a tool wear indicator to reconstruct the actual state of flank wear that cannot be measured online directly. An adaptive state observer could be obtained by adding a parameter estimator based on the recursive least-squares algorithm to the state observer model. Such an adaptive observer algorithm was developed based on a procedure given in Danai and Ulsoy (1987b).

Based on these experimental results and observation, modelling and simulation study were conducted using the proposed tool wear model. Figure 16 shows some simulation results with the model. The left diagram shows the simulated flank wear vs. the machined length (red curve). The total flank wear $W$ comprises its two components $W_{0}$ (pink curve) and $W_{1}$ (green curve) that are used as state variables. The right diagram depicts the simulated force component in $z$-direction vs. the machined length. The blue curves are the original measurement results for the parameter set $(1000 \mathrm{rpm}$ and $0.0125 \mathrm{~mm} /$ tooth) from which the model parameters have been obtained by regression analysis. It shows that the flank wear model in state observer form is capable of simulating flank wear development, provided that the model parameters are set correctly. Hence, it can be used as a state observer to reconstruct the actual state of flank wear that cannot be measured online using the measurable cutting force signal as tool wear indicator.

Figure 16 Simulation of flank wear (state variables) and the $z$-force with the tool wear model (see online version for colours)

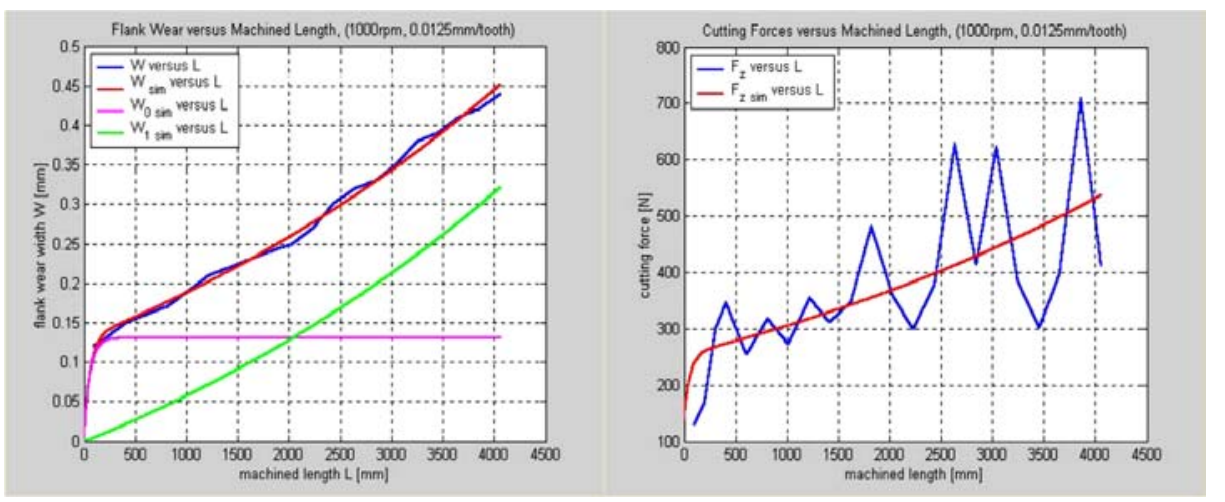

It should be pointed out that the development of such a tool wear observer model for the milling of Nickel-based alloys is still in an immature stage and there are problems that need to be further investigated. For example, as soon as some larger disturbances 
occurred in the reference signal the adaptive state observer began to become unstable and fluctuate a lot. Additionally, there was a deviation between estimated and measured flank wear width when the correlation between cutting forces, and the flank wear used in the adaptive state observer did not correspond exactly with the reality. Probably, these disturbances could be reduced to some extent by improving the cutting process by means of application of coolant and temperature regulation, reduction of tool eccentricity, grinding the sample blocks, etc.

The flank wear model depicts an exponentially increasing system which is naturally instable. It is noted that the raw force signal is not appropriate as input signal to the observer. Instead, a strongly filtered (averaged) force signal is needed. A moving average filter with a large number of averaging samples can be used for instance. To improve the performance, it is also possible to include some nonlinearity by only allowing an increase in flank wear width. If the measured forces decrease unexpectedly, the last predicted flank wear value can be used as long as the measured average force exceeds its last maximum again. If this does not work, the parameterisation of the observer gain matrix has to be changed.

\section{Conclusions}

This paper presents the development of a tool wear observer model for flank wear monitoring in the milling of Nickel-based alloys. The objective is to develop an online tool wear monitoring system that is capable of predicting tool wear development by measuring the cutting force components in real time. The experiments showed that flank wear and edge chipping were dominating. It was observed that the mean values of all the three force components increased steadily with the machined length and also with growing flank wear width, and that the increase was most obvious for the force component in the $z$-direction. A linear correlation between the cutting force components and the flank wear width was established from experimental results, which can be used in the tool wear observer model. The observer model consists of two forward branches and a feed back loop. It can be used as a state observer by using the measurable cutting force signal as tool wear indicator to reconstruct the actual state of flank wear that cannot be measured online directly. Modelling and simulation study were conducted using the proposed tool wear model and the experimental results. It shows that the flank wear model in state observer form is capable of simulating flank wear development, provided that the model parameters are set correctly. The remaining issues and further works have also been discussed.

\section{References}

Alauddin, M., Mazid, M.A., El Baradi, M.A. and Hashmi, M.J.S. (1998) 'Cutting forces in the end milling of Inconel 718', Journal of Materials Processing Technology, Vol. 77, pp.153-159.

Byrne, G. and Bienia, B. (1991) 'Tool life scatter when milling with TiN-coated HSS indexible inserts', Annals of the CIRP, Vol. 40, No. 1, pp.45-48.

Danai, K. and Ulsoy, A.G. (1987a) 'An adaptive observer for on-line tool wear estimation in turning, part I: theory', Mechanical Systems and Signal Processing, Vol. 1, No. 2, pp.211-225. 
Danai, K. and Ulsoy, A.G. (1987b) 'An adaptive observer for on-line tool wear estimation in turning, part II: results', Mechanical Systems and Signal Processing, Vol. 1, No. 2, pp. $227-240$.

Ezugwu, E.O., Olajire, K.A. and Jawaid, A. (2001) 'Wear performance of multiplayer-coated carbide tools', Machining Science and Technology, Vol. 5, No. 1, pp.115-119.

Fong, A.M., Chen, X.Q. and Li, H.Z. (2002) 'Overview of material processing automation', in Chen, X.Q., Devanathan, R. and Feng, A.M. (Eds.): Advanced Automation Techniques in Adaptive Material Processing, World Scientific Publishing Co. Pte. Ltd., pp.1-18.

Hanasaki, S., Fujiwara, J. and Touge, M. (1990) 'Tool wear of coated tools when machining a high nickel alloy', Annals of the CIRP, Vol. 39, No. 1, pp.77-80.

Iqbal, A., He, N., Dar, N.U. and Li, L. (2007) 'Comparison of fuzzy expert system based strategies of offline and online estimation of flank wear in hard milling process', Expert Systems with Applications, Vol. 33, pp.61-66.

Komanduri, R. and Schroeder, T.A. (1986) 'On shear instability in machining a Nickel-Iron base superalloy', ASME Journal of Engineering for Industry, Vol. 108, pp.93-100.

Koren, Y. (1987) 'Flank wear model of cutting tools using control theory', Journal of Engineering for Industry, Transactions of the ASME, Vol. 100, pp.103-109.

Koren, Y., Ulsoy, A.G. and Danai, K. (1986) 'Tool wear and breakage detection using a process model', Annals of the CIRP, Vol. 35, No. 1, pp.283-288.

Kuljanic, E. and Sortino, M. (2005) 'TWEM, a method based on cutting forces-monitoring tool wear in face milling', International Journal of Machine Tools and Manufacture, Vol. 45, pp.29-34.

Li, H.Z., Chen, X.Q., Zeng, H. and Li, X.P. (2007) 'Embedded tool condition monitoring for intelligent machining', Int. J. Computer Applications in Technology, Vol. 28, No. 1, pp.74-81.

Li, H.Z., Zeng, H. and Chen, X.Q. (2006) 'An experimental study of tool wear and cutting force variation in the end milling of Inconel 718 with coated carbide inserts', Journal of Materials Processing Technology, Vol. 180, Nos. 1-3, 1 December, pp.296-304.

Ng, E-G., Lee, D.W., Sharman, A.R.C., Dewes, R.C. and Aspinwall, D.K. (2000) 'High speed ball nose end milling of Inconel 718', Annals of the CIRP, Vol. 49, No. 1, pp.41-46.

Novak, A. and Wiklund, H. (1996) 'On-line prediction of the tool life', Annals of the CIRP, Vol. 45, No. 1, pp.93-96.

Park, J-J. and Ulsoy, A.G. (1992) 'On-line tool wear estimation using force measurement and a non-linear observer', Journal of Engineering for Industry, Transactions of the ASME, Vol. 114, pp.666-672.

Park, J-J. and Ulsoy, A.G. (1993a) 'On-line flank wear estimation using an adaptive observer and computer vision, part 1: theory', Journal of Engineering for Industry, Transactions of the ASME, Vol. 115, pp.30-36.

Park, J-J. and Ulsoy, A.G. (1993b) 'On-line flank wear estimation using an adaptive observer and computer vision, part 2: experiment', Journal of Engineering for Industry, Transactions of the ASME, Vol. 115, pp.37-43.

Shi, D. and Gindy, N.N. (2007) 'Tool wear predictive model based on least squares support vector machines', Mechanical Systems and Signal Processing, Vol. 21, No. 4, May, pp.1799-1814.

Weber, H. and Loladze, T.N. (1986) Grundlagen des Spanens, VEB Verlag Technik, Berlin. 